\title{
Permittivity-Inspired Microwave Resonator-Based Biosensor Based on Integrated Passive Device Technology for Glucose Identification
}

\author{
Wei Yue ${ }^{1}$, Eun-Seong Kim ${ }^{1}$ (D), Bao-Hua Zhu ${ }^{1}$, Jian Chen ${ }^{1}$, Jun-Ge Liang ${ }^{2, *}$ and Nam-Young Kim ${ }^{1, *(D)}$ \\ 1 Radio Frequency Integrated Circuit (RFIC), Kwangwoon University, Kwangwoon-ro, Nowon-gu, \\ Seoul 01897, Korea; yuewei@kw.ac.kr (W.Y.); esk@kw.ac.kr (E.-S.K.); zhuwangwhy@kw.ac.kr (B.-H.Z.); \\ cnjacob@kw.ac.kr (J.C.) \\ 2 Engineering Research Center of IoT Technology Applications (Ministry of Education), Department of \\ Electronic Engineering, Jiangnan University, Wuxi 214122, China \\ * Correspondence: jgliang@jiangnan.edu.cn (J.-G.L.); nykim@kw.ac.kr (N.-Y.K.)
}

Citation: Yue, W.; Kim, E.-S.; Zhu, B.-H.; Chen, J.; Liang, J.-G.; Kim, N.-Y. Permittivity-Inspired Microwave Resonator-Based Biosensor Based on Integrated Passive Device Technology for Glucose Identification. Biosensors 2021, 11, 508. https://doi.org/ $10.3390 /$ bios 11120508

Received: 25 October 2021

Accepted: 7 December 2021

Published: 9 December 2021

Publisher's Note: MDPI stays neutral with regard to jurisdictional claims in published maps and institutional affiliations.

Copyright: (C) 2021 by the authors. Licensee MDPI, Basel, Switzerland. This article is an open access article distributed under the terms and conditions of the Creative Commons Attribution (CC BY) license (https:/ / creativecommons.org/licenses/by/ $4.0 /)$.

\begin{abstract}
In this study, we propose a high-performance resonator-based biosensor for mediator-free glucose identification. The biosensor is characterized by an air-bridge capacitor and fabricated via integrated passive device technology on gallium arsenide (GaAs) substrate. The exterior design of the structure is a spiral inductor with the air-bridge providing a sensitive surface, whereas the internal capacitor improves indicator performance. The sensing relies on repolarization and rearrangement of surface molecules, which are excited by the dropped sample at the microcosmic level, and the resonance performance variation corresponds to the difference in glucose concentration at the macroscopic level. The air-bridge capacitor in the modeled RLC circuit serves as a bio-recognition element to glucose concentration $\left(\varepsilon_{\text {glucose }} C_{0}\right)$, generating resonant frequency shifts at $0.874 \mathrm{GHz}$ and $1.244 \mathrm{GHz}$ for concentrations of $25 \mathrm{mg} / \mathrm{dL}$ and $300 \mathrm{mg} / \mathrm{dL}$ compared to DI water, respectively. The proposed biosensor exhibits excellent sensitivity at $1.38 \mathrm{MHz}$ per $\mathrm{mg} / \mathrm{dL}$ with a wide detection range for glucose concentrations of $25-300 \mathrm{mg} / \mathrm{dL}$ and a low detection limit of $24.59 \mathrm{mg} / \mathrm{dL}$. Additionally, the frequency shift and concentration are highly linear with a coefficient of determination of 0.98823 . The response time is less than $3 \mathrm{~s}$. We performed multiple experiments to verify that the surface morphology reveals no deterioration and chemical binding, thus validating the reusability and reliability of the proposed biosensor.
\end{abstract}

Keywords: integrated passive device (IPD); glucose identification; microwave; biosensor; permittivity; air-bridge capacitor

\section{Introduction}

Owing to changing lifestyles and the prevalence of obesity worldwide, diabetes in people is increasing at an alarming rate [1]. It is the leading global cause of death resulting from severe complications, including heart attack, stroke, and kidney failure [2]. Therefore, accurate and early detection of glucose levels is essential for timely diagnosis of diabetes in overweight people and diabetic patients to monitor their health. Typically, fasting plasma glucose (FPG) standard with a blood glucose level of $70 \mathrm{mg} / \mathrm{dL}(3.9 \mathrm{mM})$ and $100 \mathrm{mg} / \mathrm{dL}$ $(5.6 \mathrm{mM})$ are considered acceptable for glucose biosensor detection [3].

Existing studies have developed glucose biosensors based on various detection technologies, such as optical, electrochemical, and microwave-based techniques [4,5]. Optical techniques analyze the optical properties and multiple responses of the sample under test (SUT) to light [6] based on selective absorption and rotatory dispersion [7]. Although optical technology is fast and non-consumable, it requires expensive analytical equipment [6]. Conversely, electrochemical methods generally exploit specific reactions or binding with SUT that occur on the surface of the distinctively modified electrodes [8-10]. 
Thus, electrochemical technology achieves high accuracy and sensitivity despite the high cost of consumable reagents and a low tolerance for environmental changes. By contrast, microwave-based technology relies on particular electromagnetic properties of SUT and offers higher stability and improved resistance to disturbances. Moreover, as it is more cost-effective than the aforementioned technologies with the potential to be non-invasive, it has been developed for glucose detection [11-14].

Most microwave biosensors adapt the resonator structure and model it as an RLC circuit, wherein the capacitor is used for bio-recognition [11]. The sensing is based on the capacitive effect derived from the interaction between SUT and electromagnetic wave and is limited by intrinsic resonator performance and reaction intensity [15]. However, the resonator is expected to have narrowband performance and a sensitive surface determined by designs, structure, and materials [15], whereas the reaction intensity is negatively correlated with the resonant frequency [16]. Most sensors use planar configurations that are optimized by designs. Sharafadinzadeh et al. reported a planar glucose biosensor based on a split ring resonator (SRR), which exhibited a $0.0008 \mathrm{MHz}$ frequency shift per $\mathrm{mg} / \mathrm{dL}$ glucose variation [17]. Liu et al. reported a planar biosensor based on a hairpin resonator for biological cell detection, reflecting each cell number in S11 magnitude at $0.83 \mathrm{~dB}$ variation [18]. Govind and Akhtar proposed a planar glucose biosensor based on SRR, incorporating the interdigital capacitor (IDC) for enhanced capacitive effect. The sensors reflected the concentration in resonant frequency variation at $0.026 \mathrm{MHz}$ per mg/dL, responding to concentrations ranging from 0 to $5000 \mathrm{mg} / \mathrm{dL}$ [19]. Manik and Muhannad proposed a glucose-responsive hydrogel-interlayer radio-frequency (RF) resonator with sensitivity of $0.333 \mathrm{MHz}$ per $\mathrm{mg} / \mathrm{dL}$ [20]. In comparison with the planar resonator, previously proposed integrated passive device (IPD) resonators with multiple layers fabricated on a low-loss gallium arsenide (GaAs) substrate exhibited complicated fabrication with higher performance by improving the substrate materials, fabrication, and structure [14-16]. However, further optimization is required for improving the sensing performance and analysis of previously reported sensors at the microcosmic and macroscopic levels when applied to glucose detection [21].

Therefore, we propose a glucose resonator-based biosensor with improved sensing performance in this study, using IPD fabrication technology and improved sensing principal analysis. The biosensor fabricated on a GaAs substrate comprises a circle-shaped spiral inductor and air-bridge capacitors on the exterior structure. The internal capacitor provides a sensitive surface and clear indicator. Furthermore, after dropping the SUT on the sensing section, the microcosmic variations in surface molecules and macroscopic responses are analyzed. The former analysis depends on two kinds of effect: the introduction of glucose and water molecules affects the electromagnetic field distribution, and the existing electromagnetic wave contributes to the polarization of the molecules. The overall transmission characterization is changed by the combined effect, reflected in S-parameter changes. The latter analysis utilized the air-bridge capacitor as the bio-recognition element to SUT permittivity, responding proportionally to $\varepsilon_{\text {glucose }} C_{0}$ and resulting in a substantially higher sensitivity of $1.38 \mathrm{MHz}$ per $\mathrm{mg} / \mathrm{dL}$ than described in existing reports. Moreover, we investigated the reusability and repeatability through multiple experiments of surface morphology to validate the high performance of the biosensor.

\section{Materials and Methods}

\subsection{Design and Optimization}

The proposed glucose microwave biosensor was developed on the basis of a resonator, wherein the resonant frequency was determined by the total inductance $\left(L_{\text {total }}\right)$ and capacitance $\left(C_{\text {total }}\right)$, as indicated in Equation (1) [22]. In this design, $L_{\text {total }}$ and $C_{\text {total }}$ are primarily derived from the exterior design, which includes the circle-shaped spiral inductance and five air-bridge capacitors, as depicted in Figure 1a. Furthermore, the inner square-shaped spiral capacitor $\left(C_{\text {inner }}\right)$ contributes to the total capacitance $\left(C_{\text {total }}\right)$ and adjusts resonance conditions for improved sensing performance. Additionally, multiple layers increase 
the mutual coupling effect, further enhancing the total inductance and capacitance and generating stronger electromagnetic intensity.

$$
f_{c}=\frac{1}{2 \pi \sqrt{L_{\text {total }} C_{\text {total }}}}
$$

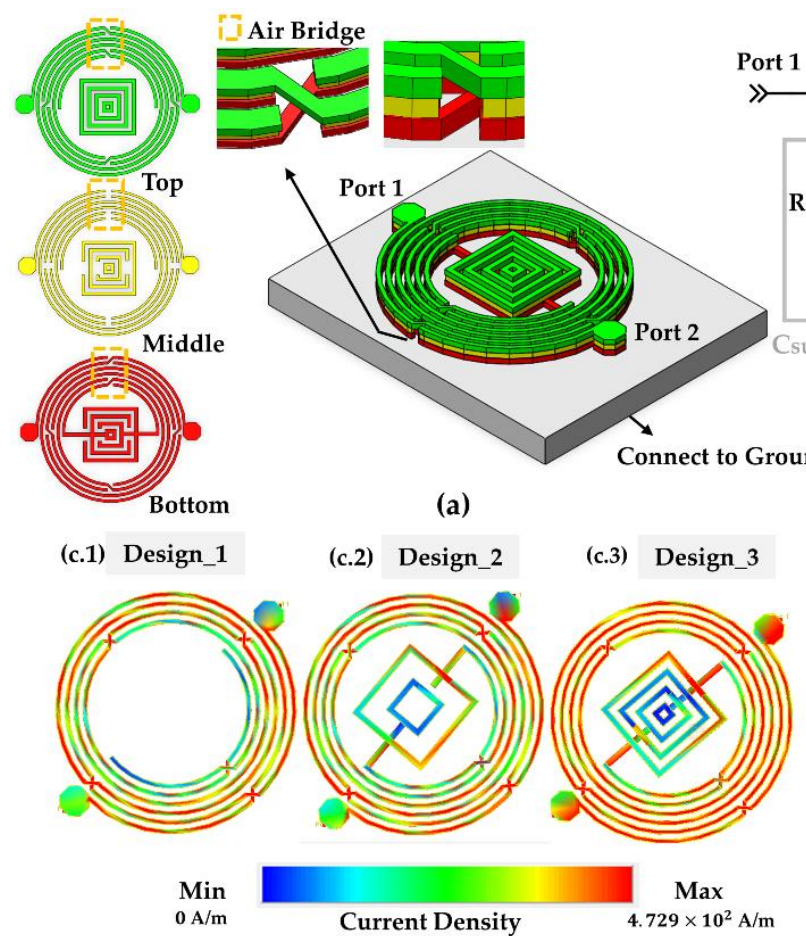

(c)
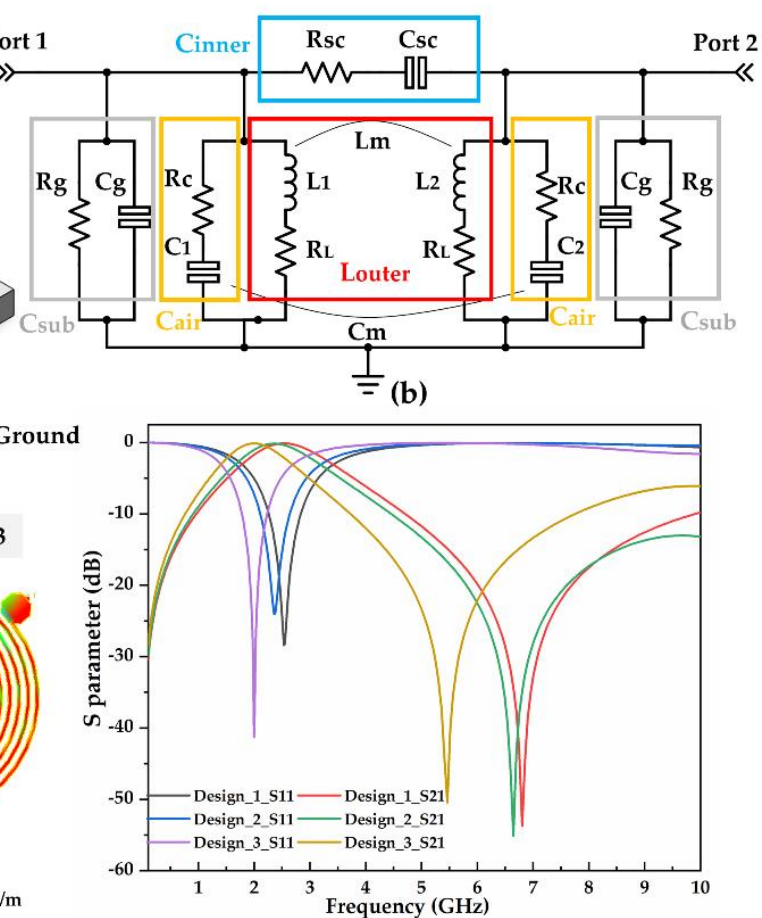

(d)

Figure 1. The conception of the proposed resonator-based biosensor: (a) The layout of the proposed biosensor with the three-layered structure; (b) The equivalent circuit of the proposed biosensor; (c) Various internal designs with current distribution conditions at the resonant frequency: (c.1) Current density distribution of Design.1; (c.2) Current density dis-tribution of Design.2; (c.3) Current density distribution of Design.3; (d) Simulated S-parameters of the designs.

Figure $1 \mathrm{~b}$ illustrates the equivalent circuit of the proposed biosensor composed of the exterior structure $\left(L_{\text {outer }}, C_{\text {air }}\right)$, the internal structure $\left(C_{s c}\right)$, and substrate structure $\left(C_{s u b}\right)$. Herein, $C_{g}$ and $R_{g}$ denote the coupling capacitance and leakage resistance, respectively, of the GaAs substrate $\left(C_{s u b}\right)$. The exterior design comprises the circle-shaped spiral inductor ( $\left.L_{\text {outer }}\right)$ and air-bridge capacitor $\left(C_{\text {air }}\right)$ that provide high inductance and capacitance with compact size, generating a strong electromagnetic field for a sensitive response. In the $L_{\text {outer }}$ section (Figure $1 b), L_{m}$ and $C_{m}$ denote the mutual inductor coupling and capacitor coupling effect, respectively. The inductance of the single-layer inductor is modeled approximately as $L_{1,2}$ based on Equation (2) [23]:

$$
L_{1,2}=\frac{\mu_{0} n^{2} d_{a v g} c_{1}}{2}\left[\ln \left(\frac{c_{2}}{\rho}\right)+c_{3} \rho+c_{4} \rho^{2}\right]
$$

where $c_{1}, c_{2}, c_{3}$, and $c_{4}$ indicate the constant coefficients of the shape of the layout [24]. Table 1 summarizes the coefficients of various shapes, such as square, hexagonal, octagonal, and circular layouts; we chose the circle shape for its highest attribution to the overall inductance [24,25]. Furthermore, $n$ and $d_{a v g}$ in Equation (2) denote the number of turns and average diameter of the circular inductor, respectively; and $\rho$ represents the fill ratio, which can be expressed using Equation (3) as:

$$
\rho=(\text { dout }-\operatorname{din}) /(\text { dout }+\operatorname{din})
$$


Table 1. Coefficients for various shapes.

\begin{tabular}{ccccc}
\hline Layout & $c_{1}$ & $c_{2}$ & $c_{3}$ & $c_{4}$ \\
\hline Square & 1.27 & 2.07 & 0.18 & 0.13 \\
Hexagonal & 1.09 & 2.23 & 0.00 & 0.17 \\
Octagonal & 1.07 & 2.29 & 0.00 & 0.19 \\
Circle & 1.00 & 2.46 & 0.00 & 0.20 \\
\hline
\end{tabular}

In this design, the multilayer inductor-capacitor (L-C) resonator consists of the bottom, middle, and top layers. Spiral metal lines are $15 \mu \mathrm{m}$ in width, the gap is $15 \mu \mathrm{m}$, and the turns on each side number 4 and 6 , respectively. Furthermore, the resonator is attached to a sub-board PCB to assist with the impedance match and common ground.

The air-bridge capacitors corresponding to $C_{a i r}$ are introduced via multiple layers with low parasitic inductance and high parasitic capacitance. In the red rectangles of the air-bridge capacitor area in Figure 1a, the middle layer provides the capacitor gap with a size of $45 \mu \mathrm{m} \times 30 \mu \mathrm{m} \times 1.8 \mu \mathrm{m}$. The bottom and top layers were designed as the capacitor plates by crossed connection with $15 \mu \mathrm{m}$ width, offering a plate area of $225 \mu \mathrm{m}^{2}$ of capacitors sensitive to the environment. In Figure $1 \mathrm{~b}, R_{c}$ denotes the resistance effect, and the capacitance of the capacitor was modeled approximately as $C_{1,2}$, calculated using Equation (4) [26]:

$$
C_{1,2}=\frac{\mathrm{S} \varepsilon_{0} \varepsilon_{r}}{\mathrm{~d}}=\varepsilon_{r} C_{0}
$$

where $\varepsilon_{0}$ denotes vacuum permittivity, $\varepsilon_{r}$ indicates the dielectric constant of interplate filling material, and $C_{0}$ represents the capacitance of intermediate vacuum medium per unit area.

Based on the aforementioned primary exterior design (Figure 1(c.1)), the electrical field distribution was simulated by the Advanced Design System (ADS) 2016.0 simulator (Keysight Technologies). Reaction densities of moderately strong current density at the surface and high current density at the air-bridge capacitor area were generated. Moreover, the indicator of a resonance condition at $2.5 \mathrm{GHz} /-28 \mathrm{~dB}$ and full width at half maximum (FWHM) of $0.7 \mathrm{GHz}$ were observed. Higher current density and peaks with lower FWHM and higher absolute value contribute to reaction density and indicator clarity. Therefore, we constructed a tunable internal capacitor structure with intense surface current density and enhanced indicator performance, which is represented as $C_{\text {inner }}$ in Figure $1 \mathrm{~b}$. The capacitance $\left(C_{S C}\right)$ was calculated using Equation (5) [23]:

$$
C_{s c}=\left[\varepsilon_{0}\left(\frac{1+\varepsilon_{s}}{2}\right) \frac{K\left(\sqrt{1+k^{2}}\right)}{K(k)}+\varepsilon_{0} \frac{t}{a}\right] L_{c}
$$

where $\varepsilon_{0}$ and $\varepsilon_{S}$ denote the permittivity of free space and GaAs substrate, respectively, $L_{C}$ indicates the total length of the spiral capacitor line, and $K(k)$ represents the first type of elliptic integral.

Figure 1c depicts the current distribution density of the exterior design (Design_1) and those with various central capacitors (Design_2 and Design_3) at the resonant frequency. Design_3 significantly promotes the current density of the external spiral inductor, generating a denser current surface with enhanced reaction density. Figure $1 \mathrm{~d}$ illustrates the S-parameter simulation of the aforementioned designs and indicator performance. As indicated in the figure, Design_3 with a resonant frequency of $2 \mathrm{GHz}$ exhibits more potential in sensing applications than Design_1 and Design_2, resulting from a lower FWHM of $0.5 \mathrm{GHz}$ and a higher magnitude value of $-42 \mathrm{~dB}$. Consequently, the glucose biosensor was fabricated using Design_3, which was selected considering its stronger reaction density and higher indicator clarity in comparison with other designs. 


\subsection{Fabrication Process}

Figure 2a depicts the fabrication process for the device, which was divided into three metal layers based on bottom-up IPD fabrication. We selected GaAs substrate as a semiinsulating material to reduce the parasitic effect significantly and increase the resonant frequency and quality of high frequency [27].

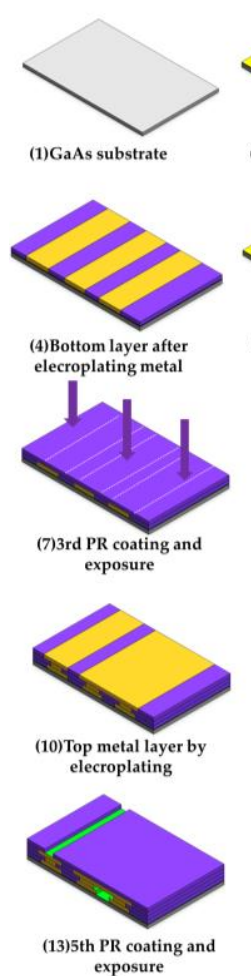

exposure

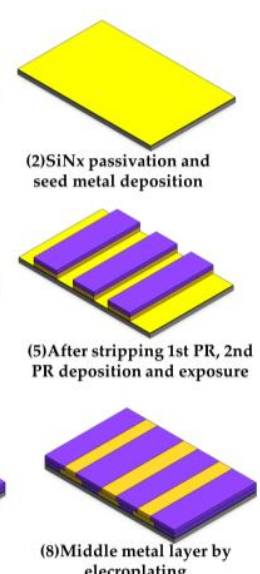

elecroplating

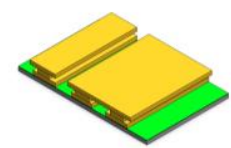

(11)PR remove

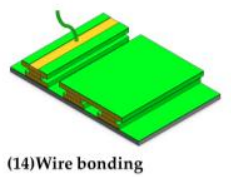

(a)

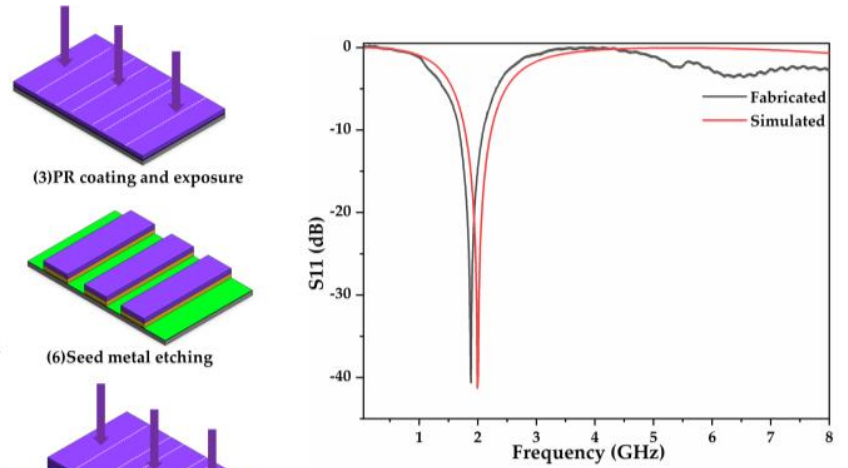

(b)

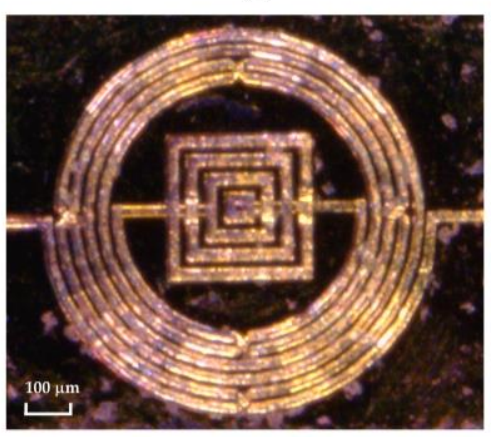

(c)

Figure 2. Fabrication process and results for the sensors: (a) The fabrication process; (b) Frequency response of the simu-lation and fabrication; (c) A microscopic picture of the fabricated biosensor.

Step 1: Before the fabrication process, the GaAs substrate $(200.1 \mu \mathrm{m})$ was pre-washed with acetone and deionized (DI) water to obtain a smoother surface with stronger layer adhesion. Steps 2-6: Initially, the silicon nitride $(\mathrm{SiNx}, 200 \mathrm{~nm})$ passivation layer was deposited on the substrate through a plasma-enhanced chemical vapor deposition process, providing strong adhesion between the metal layer and GaAs wafer. After the seed metal layer of $\mathrm{Ti} / \mathrm{Au}(20 / 80 \mathrm{~nm})$ was deposited by sputtering, the first negative photoresistor (PR) was spin-coated to define the pattern of the first metal layer. Subsequently, the first $\mathrm{Cu} / \mathrm{Au}(4.5 / 0.5 \mu \mathrm{m})$ metal layer was fabricated through electroplating. After the first PR layer was stripped by acetone solution and a lift-off machine, the second PR layer was coated and selectively exposed for the corresponding pattern with the first metal layer protecting it. Furthermore, the first seed metal layer was removed selectively.

Steps 7 and 8: A third negative PR was applied, followed by an exposed mask to define the second metal layer pattern. This defines the gap of the air-bridge capacitor. Subsequently, the second $\mathrm{Cu}(1.8 \mu \mathrm{m})$ metal layer was electroplated on the surface corresponding to the PR pattern. Steps 9-11: Another negative PR was coated, which was followed by a selectively exposed mask for the third metal layer pattern. Subsequently, a third metal layer $(\mathrm{Cu} / \mathrm{Au})$ with a thickness of $4.5 / 0.5 \mu \mathrm{m}$ was sputtered to form the top of the air bridge. The PR layers were removed, and the air-bridge structure was retained. Steps 12-14: The final passivation layer was deposited to protect against any environmental impurities. Another PR was adopted with a particular pattern to generate an open area for inductively coupled plasma dry etching. After etching and PR removal, Au wire bonding was used for the interconnection between the chip ports and the $50 \Omega$ impedance matching line, which 
was fabricated on the printed circuit board and processed for measurement, enabling its microwave performance. A bottom iron cube was connected to the multilayer structure through central via holes on the backside of the PCB board and worked as additive ground (Figure S1). Furthermore, a small outline transistor package was adopted to protect the Au wire and prevent device damage during the experiment.

As depicted in Figure 2b, minor deviations were observed during the fabrication process, unlike the simulation results, with a frequency shift of $-0.20 \mathrm{GHz}$ and $\mathrm{S} 11$ deviation of $1 \mathrm{~dB}$. Figure 2c illustrates a microscopic image of the fabricated biosensor.

\subsection{Preparation of Sample and Apparatus}

For the experiment, glucose powder, fructose powder, and glucose oxidase (GOx) were purchased from Sigma-Aldrich (St. Louis, MO, USA), and fetal bovine serum (FBS) was purchased from Welgene and stored at less than $-20^{\circ} \mathrm{C}$. All chemicals were used without further purification. The surface morphology of the developed biosensor was characterized using an atomic force microscope (AFM, FC-AM30). The S-parameter measurements were obtained using a vector network analyzer (VNA, 8719ES), measuring the frequency range from $0.05 \mathrm{GHz}$ to $8 \mathrm{GHz}$ in $0.005 \mathrm{GHz}$ steps. Microscopic images were acquired using a microscope (Dino-Lite, AM-413T).

The concentration of the glucose solution was based on the glucose level of healthy people, ranging from 70 to $125 \mathrm{mg} / \mathrm{dL}$ of FPG standard [5]; both hypoglycemia and hyperglycemia ranges were considered. Therefore, samples were prepared in the range from $25 \mathrm{mg} / \mathrm{dL}$ to $300 \mathrm{mg} / \mathrm{dL}$ in $25 \mathrm{mg} / \mathrm{dL}$ increments by dissolving the glucose powder in DI water. All samples were prepared at $26{ }^{\circ} \mathrm{C}$ and stored at $0-4{ }^{\circ} \mathrm{C}$.

\section{Results and Discussion}

\subsection{Characterization and Experimental Process}

Figure 3 depicts the device, packed with a $50 \Omega$ port for impedance match, connected to the VNA. Before glucose solution measurement, initially, the glucose level identification experiments recorded the bare chip and DI water droplet S-parameters as a reference. Subsequent tests were performed after washing and drying the surface. After several tests in groups, the sensor surface was rinsed with phosphate buffered saline (PBS) and water and dried through a nitrogen drying process. This was followed by another measurement of bare chip S-parameters.

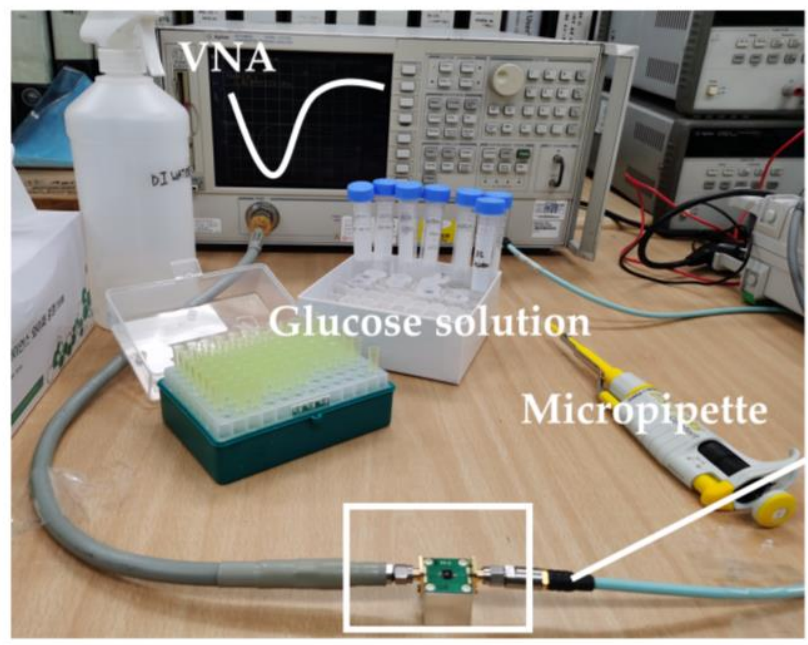

(a)

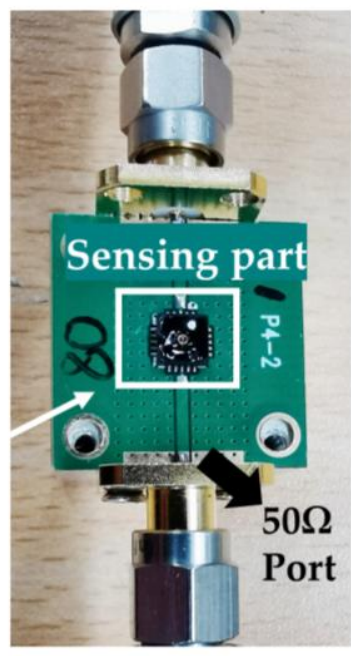

(b)

Figure 3. Experimental setup for the tests. (a) The experimental setup and preparation for the meas-urement of glucose level. (b) The tested device connected to a vector network analyzer (VNA) through a $50 \Omega$ port. 
Moreover, to further demonstrate the potential for clinical applications of the sensor, GOx was added because of its specific reaction to glucose (Figure S5) [28]. After measuring the responses to $5 \mu \mathrm{L} 100 \mathrm{mg} / \mathrm{dL}$ glucose and fructose serum solution as the control group, mixed $3 \mu \mathrm{L}$ glucose oxidase solution (no catalyst, 16.80 units), and $2 \mu \mathrm{L} 100 \mathrm{mg} / \mathrm{dL}$ glucose and fructose serum solution, the reaction time was set at $10 \mathrm{~min}$.

\subsection{Reusability and Repeatability}

Before performing glucose identification experiments, we investigated the reliability of the biosensor based on the consistency of performance derived from multiple experiments with the $150 \mathrm{mg} / \mathrm{dL}$ glucose solution at the macroscopic level (Figure 4a). Periodic detection was performed 6 times, and the observed high consistency verified the repeatability of the sensor for glucose identification with a relative standard deviation (RSD) of $0.11 \%$. Moreover, the reusability was determined by comparing the resonance performance of the unloaded chip before and after the tests, as illustrated in Figure $4 \mathrm{~b}$. When the droplet residue or impurity remains on the surface, the center frequency shifts by approximately $0.1 \mathrm{GHz}$ from the unloaded condition and returns to the unloaded condition after being rinsed with PBS/DI water. Typically, the results for the same concentration and the unloaded performance are highly consistent, validating that no apparent frequency deterioration or shift occurs in the entire process. Thus, the sensor can be considered highly reliable and reusable.

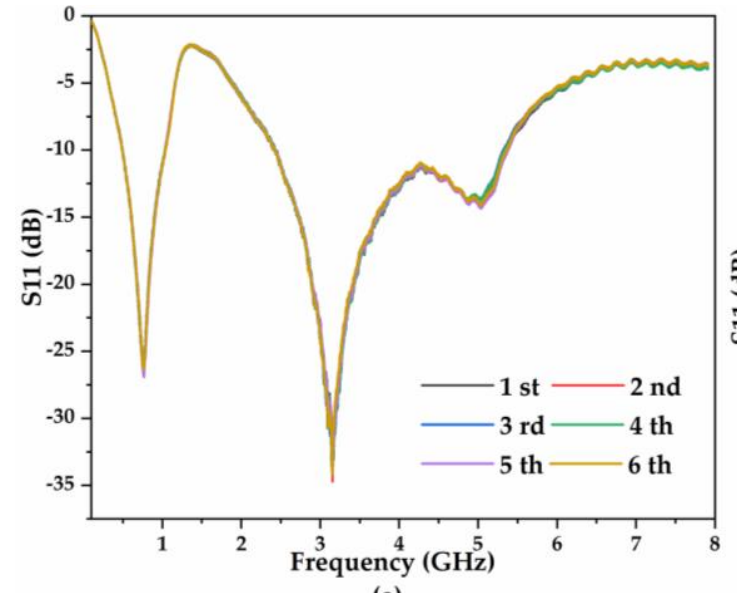

(a)

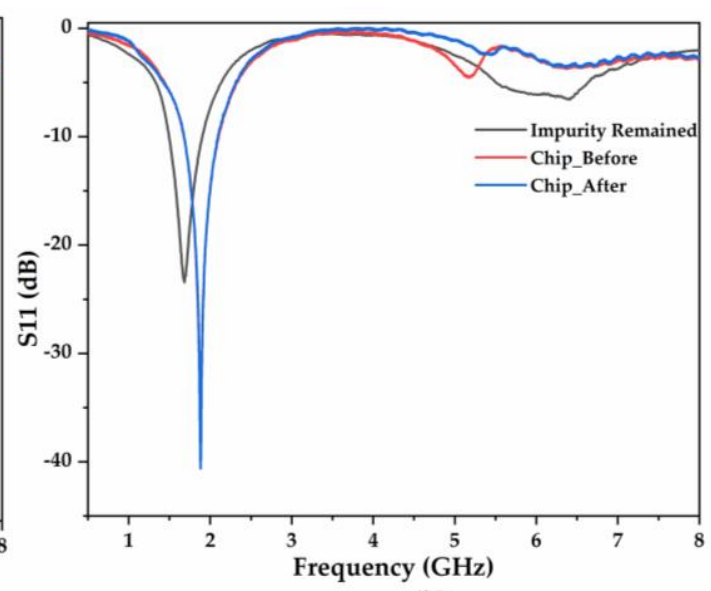

(b)

Figure 4. Pre-reliability and reusability investigation. (a) Six experiments for testing the $150 \mathrm{mg} / \mathrm{dL}$ glucose solution. (b) Unloaded chip resonance performance before and after the experiment.

To further facilitate reusability and reliability at the microcosmic level, we measured and compared the surface morphology maps before and after the experiment. The root mean square (RMS) value represents the average profile height and indicates the surface roughness level and damaged condition in various scenarios. Figure 5 depicts the characteristics of three states of the chip surface, namely (a) the unloaded chip before cleaning, (b) the unloaded chip surface before the experiment, and (c) the unloaded chip surface after repeating the experiment more than 15 times.

Figure 5(a.1,a.2,a.3) illustrate the unloaded unpackaged biosensor before cleaning, wherein the RMS value of $68.15 \mathrm{~nm}$ is presented in two-dimensional (2-D) and threedimensional (3-D) representations. Following washing, we observed that the RMS value decreased to $22.49 \mathrm{~nm}$ before the experiment, as depicted in Figure 5(b.2). The apparent change implies that the invisible impurities that existed during storage were removed, verifying that cleaning before the test was necessary. As the chip with the droplet could not be tested by the AFM equipment because of its probe distance limitation, we considered the same unloaded biosensor after the experimental process with an RMS value of $19.73 \mathrm{~nm}$ (Figure 5(c.3)). The RMS values of the chip before and after the experiment exhibited 
only a minor deviation. Moreover, the surface profile results indicated high consistency between the groups before and after the experiment, as depicted in Figure 5(c.1,c.2,c.3). The obtained results verified that no chemical immobilization or deterioration on the surface occurred and no frequency shift was generated during the experiment. Thus, the high reusability and reliability of the sensor at both microcosmic and macrocosmic levels could be validated.
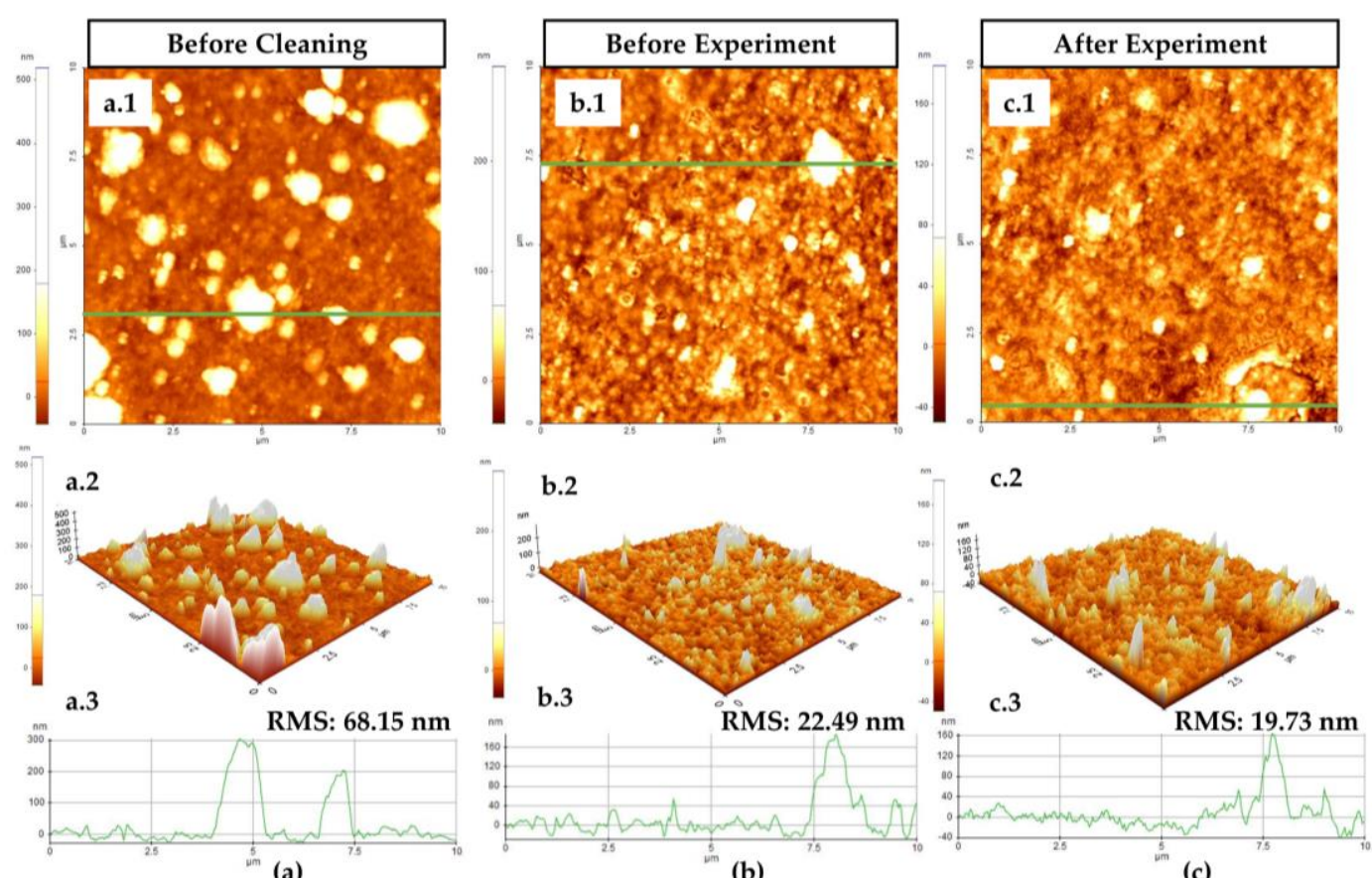

Figure 5. Surface morphological conditions. (a) Before cleaning: (a.1) the two-dimensional (2-D) view of the unloaded surface; (a.2) the three-dimensional (3-D) surface profile; (a.3) the line profile for surface roughness distribution of green line. (b) Unloaded chip condition before the experiment: (b.1) the 2-D view of the surface condition; (b.2) the 3-D surface profile; (b.3) the line profile distribution of green line; (c) Chip condition after multiple experiments: (c.1) the 2-D view of the surface condition; (c.2) the 3-D surface profile; (c.3) the line profile for surface roughness distribution of green line.

\subsection{Sensing Response Analysis}

We selected S11 as the reference signal owing to its high resistance to environmental interference in multiple electromagnetic transmission parameters. To evaluate the S11 response of the biosensor to the introduced liquid, DI water was used as a reference and compared with the unloaded condition depicted in Figure 6a. Additionally, serum and $100 \mathrm{mg} / \mathrm{dL}$ glucose aqueous solution were added and compared, inducing various responses from the sensor. The bare biosensor resonant frequency at $1.80 \mathrm{GHz}$ shifted to two peaks of $1.054 \mathrm{GHz} /-29.354 \mathrm{~dB}$ and $3.958 \mathrm{GHz} /-44.089 \mathrm{~dB}$ for DI water. Herein, the former was considered the decrease from the original frequency of $1.80 \mathrm{GHz}$ because of the air-bridge capacitive effect of the sample; the latter was evaluated as the introduced sample capacitance-like effect (Figure S2). Moreover, no overlap occurred between the responses to different concentrations at the resonant frequency in Figure $6 \mathrm{~b}, \mathrm{~d}$, validating its high sensitivity to support subsequent analysis. 


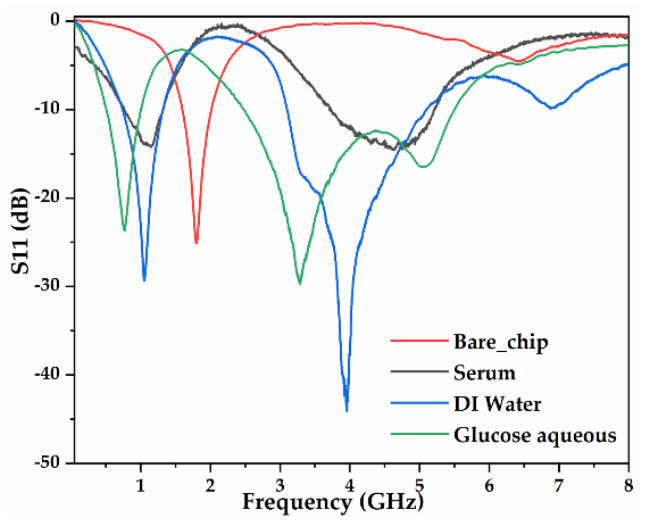

(a)

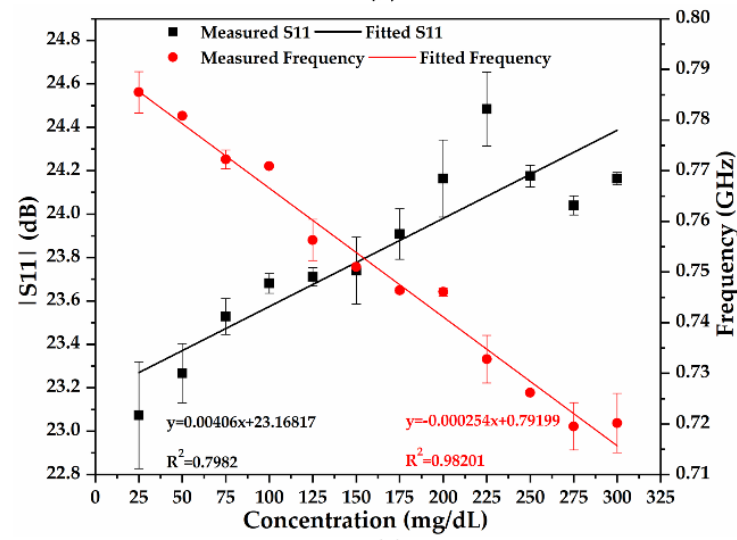

(c)

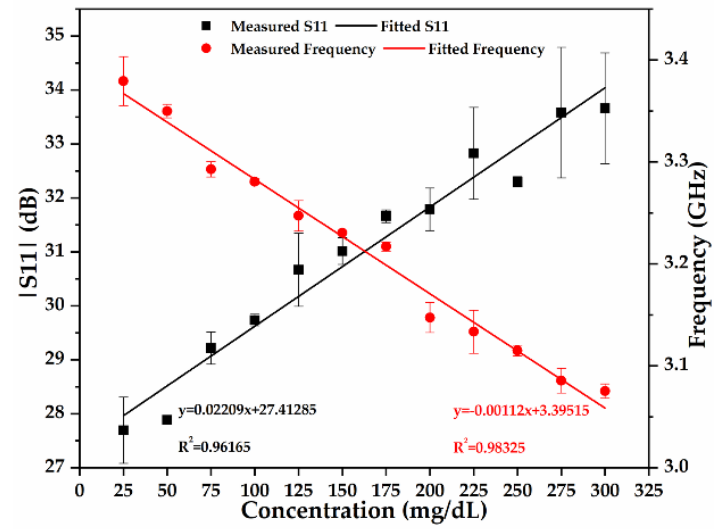

(e)

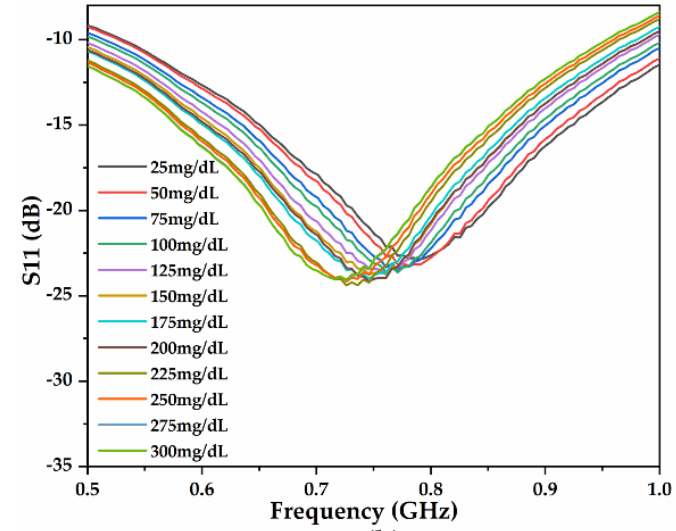

(b)

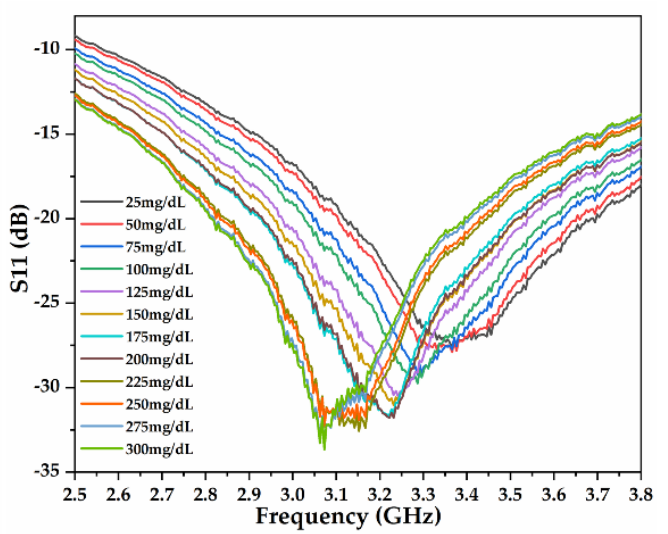

(d)

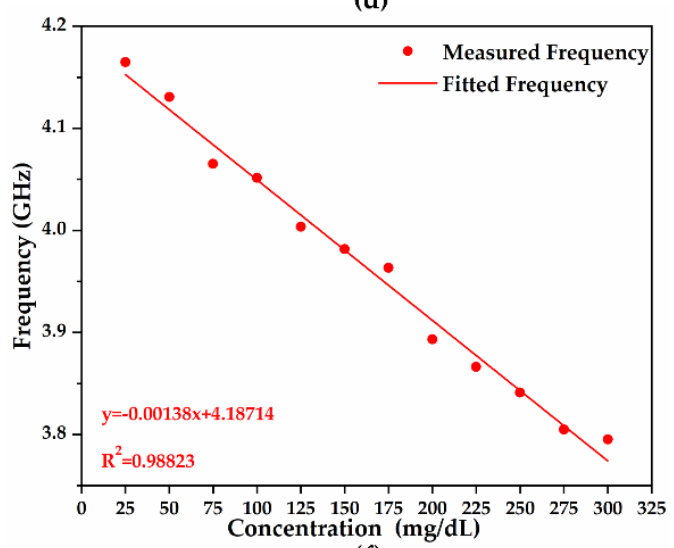

(f)

Figure 6. Microwave response under various conditions: (a) DI water, serum, and $100 \mathrm{mg} / \mathrm{dL}$ glucose aqueous responses compared with the unloaded chip; (b) resonant frequency responses of various concentrations at peak $0.8 \mathrm{GHz}$ (c) the linear analysis at $0.8 \mathrm{GHz}$ peak of multiple concentrations with error bars; (d) the peak response at $3.2 \mathrm{GHz}$ to multiple concentrations; (e) the linear analysis at $3.2 \mathrm{GHz}$ peak of multiple concentrations with error bars; (f) summation of the relationship between two peak conditions at various concentrations.

Figure $6 \mathrm{~b}, \mathrm{c}$ illustrate the frequency of approximately $0.8 \mathrm{GHz}$ for peak 1 , wherein both amplitude and center frequency differ from linear differential relativity based on various glucose concentrations. The S-parameters were measured three times for each concentration sample to reduce the error, which resulted in a highly consistent standard deviation. The frequency exhibited a linear downtrend from $0.786 \mathrm{GHz}$ to $0.720 \mathrm{GHz}$ as glucose levels increased from $25 \mathrm{mg} / \mathrm{dL}$ to $300 \mathrm{mg} / \mathrm{dL}$ with a fitting curve coefficient of determination (COD) of 0.9820 and a maximum RSD of $0.81 \%$ at $300 \mathrm{mg} / \mathrm{dL}$. Additionally, the absolute value of its amplitude increased linearly from 23.073 to $24.164 \mathrm{~dB}$ when glucose levels increased, with the lowest COD of 0.7982 in comparison with the frequency. The 
maximum frequency shift of $0.334 \mathrm{GHz}$ was generated at $300 \mathrm{mg} / \mathrm{dL}$ glucose aqueous concentration level compared to DI water, with a sensitivity of $0.254 \mathrm{MHz}$ per mg/dL.

In the case of peak 2, the frequency was approximately $3.2 \mathrm{GHz}$, with both amplitude and center frequency differing when tested with samples of various concentrations (Figure $6 \mathrm{~d}$ ). The resonant frequency of the solution primarily ranged from 3.379 to $3.075 \mathrm{GHz}$ for glucose concentrations varying from $25 \mathrm{mg} / \mathrm{dL}$ to $300 \mathrm{mg} / \mathrm{dL}$ with a COD of 0.98325 , exhibiting a highly linear relationship. The maximum RSD of $0.71 \%$ was observed at $25 \mathrm{mg} / \mathrm{dL}$, which indicates excellent reproducibility among all samples [16]. The absolute value of its amplitude also increased linearly from 23.452 to $33.661 \mathrm{~dB}$ when the glucose levels increased, with the lowest COD of 0.9617 in comparison with the frequency. The proposed device generated a maximum frequency shift of $0.883 \mathrm{GHz}$ at $300 \mathrm{mg} / \mathrm{dL}$. Additionally, this peak exhibited a sensitivity of $1.2 \mathrm{MHz}$ per mg/dL.

The peak at $3.2 \mathrm{GHz}$ indicates a better correlation than that at $0.8 \mathrm{GHz}$, with the further analysis of the corresponding relationship between frequency and concentrations, matching a linear fitted curve, as depicted in Figure 6e. The calibration curves were fitted using Equation (6):

$$
y=-0.00107 x+3.39102
$$

where $y$ represents the center frequency $(\mathrm{GHz})$ and $x$ denotes the concentrations of glucose aqueous solutions $(\mathrm{mg} / \mathrm{dL})$.

Figure $6 \mathrm{f}$ illustrates the summation of frequencies of peaks 1 and 2. This analysis was performed due to the higher linearity of the frequency to the magnitude and similar downtrend response to the increase in glucose concentration. The summation enhanced the detection and reduced errors, resulting in a higher sensitivity of $1.38 \mathrm{MHz}$ per $\mathrm{mg} / \mathrm{dL}$ and an increased correlation with improved COD of 0.9882 . The calibration curves were fitted using Equation (7):

$$
\begin{gathered}
y=-0.00138 x+4.18714 \\
\text { Glucose concentration }_{\left(\frac{m g}{d L}\right)}=\frac{4.18714-\left(f_{r 1}+f_{r 2}\right)}{0.00138}
\end{gathered}
$$

The response results verified that the output response of the proposed glucose biosensor ranges from 25 to $300 \mathrm{mg} / \mathrm{dL}$ with high sensitivity for resonance frequencies of $0.254 \mathrm{MHz}$ at peak $1(0.8 \mathrm{GHz})$ and $1.20 \mathrm{MHz}$ at peak $2(3.2 \mathrm{GHz})$. The summation of peaks 1 and 2 with improved COD of 0.9882 further enhanced the sensitivity up to $1.38 \mathrm{MHz}$ per $\mathrm{mg} / \mathrm{dL}$. Moreover, the results of variations in serum concentration are shown in Figure S6, revealing the same trend between resonance frequency and concentration.

The glucose sensing limit of detection (LOD), was calculated by using the following Equation (9) as $24.59 \mathrm{mg} / \mathrm{dL}[29,30]$.

$$
L O D=3.3 \times S D / m
$$

where $\mathrm{SD}$ is the standard deviation of the sensing response to glucose solution and $\mathrm{m}$ is the slope of the fitted curve. Additionally, the RSD was calculated as less than 1\% (Table S1), and response time was less than $3.3 \mathrm{~s}$ (Table S2).

Table 2 compares the sensitivity and other performance measures of the proposed IPD biosensor with other resonator-based microwave biosensors. As indicated in the table, the proposed biosensor exhibits substantially higher sensitivity and correlation across multiple microwave biosensors. 
Table 2. Comparison of glucose biosensor performance.

\begin{tabular}{|c|c|c|c|c|c|}
\hline References & Structure & $\begin{array}{l}\text { Sensing } \\
\text { Method }\end{array}$ & $\begin{array}{c}\text { Operation } \\
\text { Frequency } \\
\mathrm{f}_{0}(\mathrm{GHz})\end{array}$ & $\begin{array}{c}\text { Concentration } \\
\text { Range } \\
\text { (mg/dL) }\end{array}$ & $\begin{array}{c}\text { Sensitivity } \\
\text { (MHz per } \\
\text { mg/dL) }\end{array}$ \\
\hline [16] & LC resonator & $\mathrm{f}_{\mathrm{r}}, \mathrm{S}_{11}$ & 0.6 & $30-500$ & 1.175 \\
\hline [19] & SRR & $\mathrm{f}_{\mathrm{r}}$ & 1.4 & $0-5000$ & $2.60 \times 10^{-2}$ \\
\hline [31] & LC resonator & $\mathrm{f}_{\mathrm{r}}, \mathrm{S}_{11}$ & 1.4 & $0-72$ & $2.6 \times 10^{-6}$ \\
\hline [32] & CELC & $\mathrm{f}_{\mathrm{r}}$ & 1.3 & $0-10,000$ & $2.11 \times 10^{-2}$ \\
\hline [33] & $\begin{array}{c}\text { ENG } \\
\text { unit-cell }\end{array}$ & $\mathrm{f}_{\mathrm{r}}, \mathrm{S}_{21}$ & 1.6 & $2000-10,000$ & $1.00 \times 10^{-2}$ \\
\hline [34] & $\lambda / 4$ resonator & $\mathrm{f}_{\mathrm{r}}, \mathrm{S}_{11}$ & 1.68 & $0-30,000$ & $1.68 \times 10^{-3}$ \\
\hline [35] & CSRR & $\mathrm{f}_{\mathrm{r}}$ & 2.45 & $40-140$ & $6.3-12.5 \times 10^{-1}$ \\
\hline [36] & $\begin{array}{c}\text { Patch } \\
\text { antenna }\end{array}$ & $\mathrm{f}_{\mathrm{r}}$ & 5.0 & $0-250$ & $1.09 \times 10^{-3}$ \\
\hline [37] & Cavity & $\mathrm{f}_{\mathrm{r}}, \mathrm{S}_{11}$ & 4.75 & $150-550$ & $2.80 \times 10^{-2}$ \\
\hline [38] & CSRR & $\mathrm{f}_{\mathrm{r}}, \mathrm{S}_{11}$ & 2.5 & $0-500$ & $0.50 \times 10^{-2}$ \\
\hline $\begin{array}{l}\text { Proposed } \\
\text { biosensor }\end{array}$ & $\begin{array}{c}\text { IPD } \\
\text { LC-resonator }\end{array}$ & $f_{r}, S_{11}$ & $0.8,3.2$ & $25-300$ & 1.38 \\
\hline
\end{tabular}

\subsection{Microcosmic Sensing Principle and Specificity}

The sensing principle was developed at both microcosmic and macrocosmic levels to quantify the influence of the introduced SUT discussed in radio frequency and microwave frequency $(30 \mathrm{kHz} 30 \mathrm{GHz})$. At the microcosmic level, all particles tend to remain in dynamic equilibrium, maintaining the lowest energy state. When electromagnetic waves change the environmental conditions, the original state of molecules is disturbed through various types of polarization, leading to rearrangement. The polarization type is excited by the electromagnetic frequency; polarization density is decided by electrical field density $[11,30]$. Based on the detection frequency range $(0.05 \mathrm{GHz} 8.0 \mathrm{GHz})$ and liquid sensing condition, only the dipole polarization contribution to permittivity was considered, as illustrated in Figure 7a [11]. Dipole polarization performs an adaptive overall molecule rotation in the direction of the electric field. The polarization density $(P)$ and relative permittivity $\left(\varepsilon^{\prime}\right)$ can be represented by using Equations (10) and (11) [11]:

$$
\begin{gathered}
P=\left(\varepsilon^{\prime}-1\right) \varepsilon_{0} E=\alpha_{t} E^{\prime} N^{\prime} \\
\varepsilon^{\prime}=\frac{\alpha_{t} E^{\prime} N^{\prime}}{\varepsilon_{0} E}+1
\end{gathered}
$$

where $\varepsilon^{\prime}, \varepsilon_{0}$ and $E$ are macroscopic parameters: $\varepsilon^{\prime}$ represents the relative permittivity because of the polarization, $\varepsilon_{0}$ denotes the free space permittivity, $E$ represents the existing local electrical field, and $E^{\prime}$ represents the net field as a combined effect of local field $(E)$ and induced opposed field by induced dipoles. $\alpha_{t}$ and $N^{\prime}$ represent microscopic molecular parameters: $\alpha_{t}$ denotes the polarizability derived from the various polarizations, $N^{\prime}$ represents the number of individual dipole moments. Through this equation, the polarization density is influenced by dipole number $N^{\prime}$ and net field $E^{\prime}$ as well as the polarizability $\alpha_{t}$. Additionally, the relative permittivity derived from the dipole number $N^{\prime}$ contributes to total polarization and polarizability.

Herein, our sensing sample materials were composed of water and glucose molecules with frequencies at $0.8 \mathrm{GHz}$ and $3.2 \mathrm{GHz}$; the polarization $\left(\alpha_{t}\right)$ mainly consisted of the dipole polarization $\left(\alpha_{d}\right)$, following Equations (12) and (13) [30]:

$$
u=q l
$$




$$
\alpha_{d}=\frac{u^{2}}{3 k T}, u E \ll k T
$$

where $u$ is the permanent dipole moment depending on dipole type, $l$ is the distance between $+q$ and $-q$ shown in Figure $7 \mathrm{~b}$. Hence, the permittivity depends on the field density when sensing the fixed SUT in a frequency-varying electromagnetic field. When sensing in a fixed field $(E)$, the permittivity depends on the dipole type, internal structure, and number. We considered glucose and fructose as a comparison group; glucose appears more polar because of its asymmetric construction, contributing to higher polarizability and sensitivity permittivity variation to frequency [30].
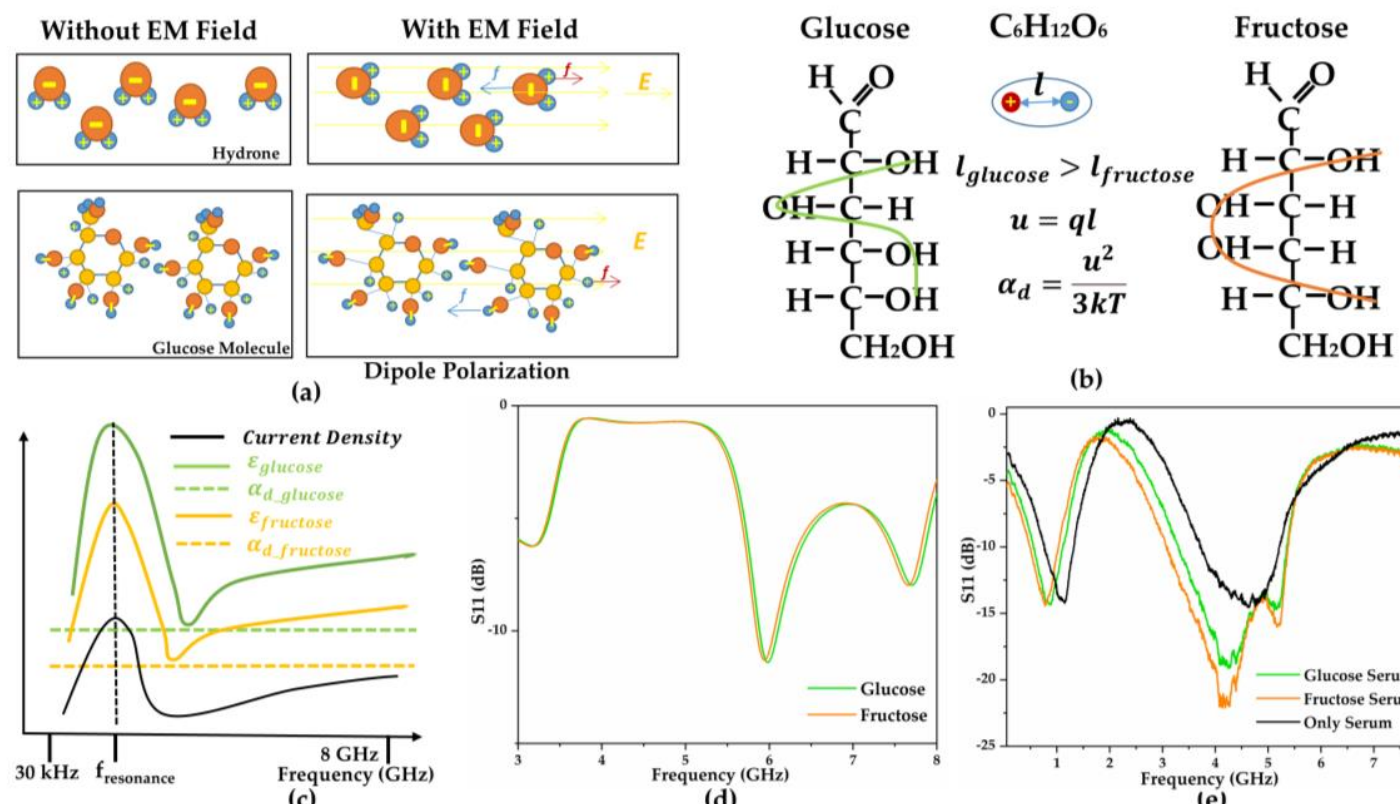

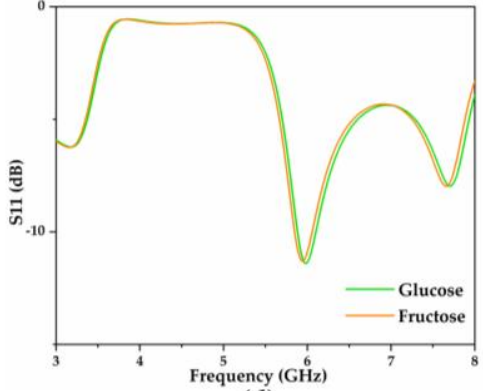

(d)

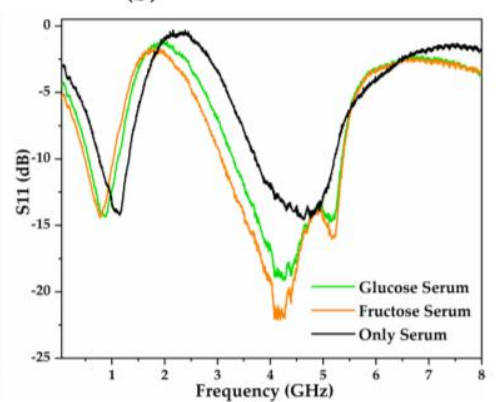

(e)

Figure 7. (a) Water and glucose molecule dipole polarization with and without the electromagnetic (EM) field. (b) Glucose and fructose original structure and polarizability comparison. (c) Glucose and fructose polarizability and permittivity response to current density. (d) Glucose and fructose simulation response and (e) measured results for $100 \mathrm{mg} / \mathrm{dL}$ glu-cose/fructose in serum compared to pure serum.

As a result, Figure $7 \mathrm{c}$ illustrates the average current density responding to the frequency, corresponding polarizability, and permittivity variation. In addition, we simulated and measured the $100 \mathrm{mg} / \mathrm{dL}$ glucose and fructose serum solutions and their various responses, demonstrating the specificity of the proposed sensor, as depicted in Figure 7d,e. Herein, the resonance occurring in the equilibrium condition represented the maximum electromagnetic transmission at that frequency with the slightest loss [39]. Furthermore, the amplitude of the electromagnetic oscillation attained its peak, which was reflected in the peak of S11.

Based on the above theory, electromagnetic sensing provides the ability to determine various materials even with the same chemical formula because of the different frequency responses that derive from their internal structures and multiple concentrations due to diverse responses derived from the dipole number. From this perspective, there are two optimization methods for improving selectivity: increasing the surface current density to enhance the response difference, or assisting chemical bonding to emphasize the material. We investigated the latter approach through the utilization of GOx and various combination methods as shown in Figures S3 and S4, demonstrating the specific chemical combination effective in strengthening response specificity. 


\subsection{Macroscopic Sensing Analysis}

At a macroscopic level, also viewed as the device level, the dropped glucose analyte is regarded as a new filling medium with enhanced permittivity. Based on the equivalent circuit model illustrated in Figure $1 \mathrm{~b}$ and calculations of Equations (1) and (4), the increase in total capacitance decreases the resonant frequency, which primarily relies on glucose permittivity. The ideal complex permittivity of glucose solutions, composed of real and imaginary parts, can be extracted from the Debye relaxation model and represented using Equation (14) [40]:

$$
\varepsilon_{g}=\varepsilon_{\text {real }}-j \varepsilon_{\text {imag }}=\left[\frac{\left(\varepsilon_{s}-\varepsilon_{\infty}\right)}{1+\omega^{2} \tau^{2}}+\varepsilon_{\infty}\right]+j\left[\frac{\left(\varepsilon_{s}-\varepsilon_{\infty}\right) \omega \tau}{1+\omega^{2} \tau^{2}}\right]=\varepsilon_{\infty}+\sum_{k=1}^{p} \frac{\Delta_{\varepsilon k}}{1+j \omega \tau_{k}}
$$

where $\omega$ represents the angular frequency, $\omega=2 \pi f ; p$ denotes the fitting order of the Debye model, $p=1 ; \varepsilon_{\infty}$ indicates the relative permittivity at infinite frequency; and $\Delta_{\varepsilon k}$ and $\tau_{k}$ denote the dispersion values and relaxation time, respectively. The aforementioned values are estimated using the fitted curve based on the measured values, as indicated in Equations (15)-(17) [40]:

$$
\begin{aligned}
& \varepsilon_{\infty}=c_{\text {glucose }}^{2} \times 1.073 \times 10^{-6}+c_{g} \times 2.29 \times 10^{-3}+9.824 \\
& \Delta_{\varepsilon k}=c_{\text {glucose }}^{2} \times 0.916 \times 10^{-6}-c_{g} \times 2.29 \times 10^{-3}+69.28 \\
& \tau_{k}=c_{\text {glucose }}^{2} \times 0.2156 \times 10^{-7}-c_{g} \times 0.276 \times 10^{-3}+9.21
\end{aligned}
$$

where $c_{\text {glucose }}$ represents the glucose concentration $(\mathrm{mg} / \mathrm{dL})$. The calculated permittivity values of various glucose concentrations were approximately 78 , which also could be extracted by artificial neural networks [41].

Figure 8a depicts the surface molecule distribution corresponding to surface current density, while Figure 8b,c compares the analysis and simulation of unloaded and dropped conditions equivalently. Considering the dropped analyte as the filling medium, the value of medium permittivity $\left(\varepsilon_{0}\right)$ at 1 increased to several dozens $\left(\varepsilon_{\text {glucose }}\right)$ based on Equation (4). Additionally, the air-bridge capacitance $C_{0}$ increased to $\varepsilon_{\text {glucose }} C_{0}$ and contributed to the overall increase in the device capacitance, which decreased the resonant frequency to the corresponding value based on Equation (1). The resonant frequency exhibited an evident decline from $2 \mathrm{GHz}$ to $0.571 \mathrm{GHz}$ through a simulation based on the change in filling medium permittivity from 1 to 78 .

Furthermore, considering the permittivity change principle, the frequency detection resolution (FDR) was defined and represented as the ratio of resonant frequency to the variation in dielectric constant derived from concentrations, as indicated in Equations (18) and (19) [42]:

$$
\begin{gathered}
\Delta f_{r}=f_{r}(\text { loaded })-f_{r}(\text { unloaded }) \\
F D R=\frac{\Delta f_{r}}{\Delta_{\varepsilon r}}
\end{gathered}
$$

where $\Delta_{\varepsilon r}$ represents the change in permittivity of the sample. The relationship between the frequency shift and exported glucose permittivity could be calculated using Equations (15)-(17). As the proposed biosensor exhibits an FDR of $464 \mathrm{MHz}$ for each unit permittivity variation, it can be used as a candidate to detect other aqueous samples with various values of permittivity. 

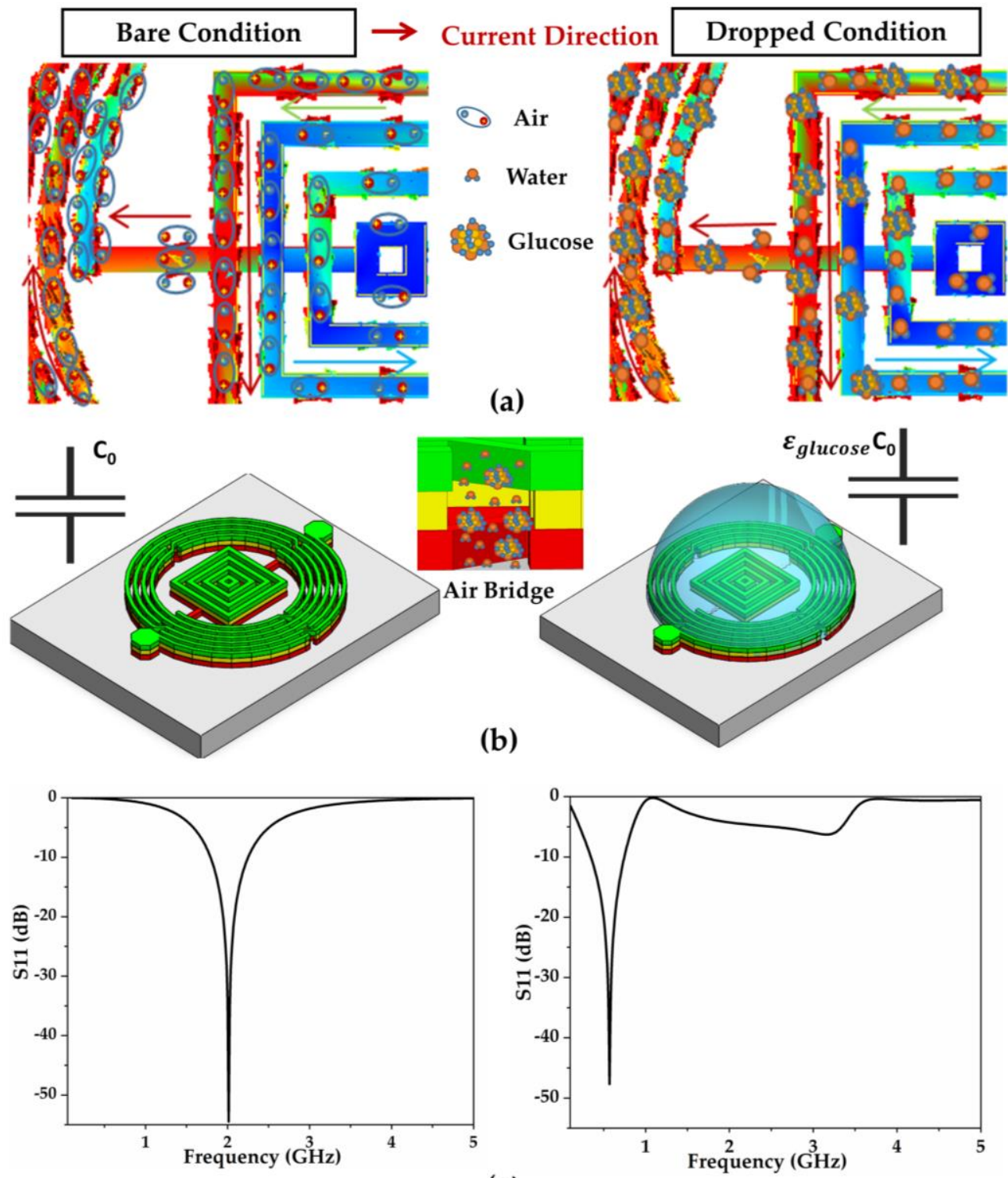

(c)

Figure 8. Comparison of bare and dropped condition. (a) Molecular polarization condition corresponding to current di-rection. (b) Corresponding equivalent capacitor. (c) Resonance simulation corresponding to without and with SUT.

\section{Conclusions}

To identify the glucose level in an aqueous solution, we propose a reusable microwave resonator-based biosensor fabricated using IPD technology. The proposed biosensor detected glucose at concentrations ranging from 25 to $300 \mathrm{mg} / \mathrm{dL}$, with a sensitivity of 1.20 MHz per mg/dL, and showing an LOD of $24.59 \mathrm{mg} / \mathrm{dL}$. Additionally, an optimization method for analyzing the summation of two peak frequencies improved the linear relationship corresponding to various glucose concentrations with a sensitivity of $1.38 \mathrm{MHz}$ per mg/dL. Thus, the sensitivity of the biosensor was substantially higher than those of existing biosensors. Further considerations for the sensing microcosmic principle and the macroscopic analysis based on the RLC circuit were discussed. Moreover, the periodic detection and morphological analysis showed that no frequency deterioration and chemical binding occurred during the entire experiment, thus validating the reusability and reliability of the biosensor for real-time glucose detection. The permittivity response was investigated with a sensitivity of $466 \mathrm{MHz}$ for unit permittivity variation, implying 
the proposed biosensor can potentially detect biological aqueous solutions with various permittivity differences. Meanwhile, the GOx-assisted approach increased the biosensor's selectivity to glucose through the specific reaction between GOx and glucose, proving its potential in clinical application.

Supplementary Materials: The following are available online at https:/ / www.mdpi.com/article/10 .3390/bios11120508/s1, Figure S1: Unpackaged chip. (a) Front side with Au wire bonding connecting to 50-ohm matching line; (b) backside with via holes. Figure S2: Different liquid volume response curves. Figure S3: The variations in response of $100 \mathrm{mg} / \mathrm{dL}$ glucose and fructose dissolved in serum with/without glucose oxidase. Figure S4: Different mixture response curves. Figure S5: Reaction principle. Figure S6: Response curves for different glucose concentrations in serum. Table S1: RSD calculation of the peak 2 frequency. Table S2: $8719 \mathrm{E}$ full frequency band sweep time (0.05 to $13.5 \mathrm{GHz} \mathrm{ms})$.

Author Contributions: Conceptualization, W.Y.; software, W.Y. and J.C.; validation, E.-S.K.; formal analysis, W.Y. and B.-H.Z.; investigation, J.-G.L.; writing-original draft preparation, W.Y.; writing-review and editing, W.Y. and J.-G.L.; visualization, W.Y; supervision, N.-Y.K. and J.-G.L.; project administration, N.-Y.K.; funding acquisition, N.-Y.K. All authors have read and agreed to the published version of the manuscript.

Funding: This work was supported in part by the Basic Science Research Program through the National Research Foundation of Korea (NRF) funded by the Ministry of Education under Grant 2018R1A6A1A03025242 and Grant 2018R1D1A1A09083353, and in part by the Korea Ministry of Environment (MOE) Graduate School specialized in Integrated Pollution Prevention and Control Project and a Research Grant of Kwangwoon University in 2021. The authors are also thankful for the General Financial Grant from the China Postdoctoral Science Foundation (2020M671439, 2020T130283), National Natural Science Foundation of China (61903160), Natural Science Foundation of Jiangsu Province (BK20190581). This work was also partly supported by the Fundamental Research Funds for the Central Universities (JUSRP51510).

Institutional Review Board Statement: Not applicable.

Informed Consent Statement: Not applicable.

Data Availability Statement: Not applicable.

Conflicts of Interest: The authors declare no conflict of interests.

\section{References}

1. Forouhi, N.G.; Wareham, N.J. Epidemiology of diabetes. Medicine 2014, 42, 698-702. [CrossRef] [PubMed]

2. Deshpande, A.D.; Harris-Hayes, M.; Schootman, M. Epidemiology of diabetes and diabetes-related complications. Phys. Ther. 2008, 88, 1254-1264. [CrossRef] [PubMed]

3. Association, A.D. Diagnosis and classification of diabetes mellitus. Diabetes Care 2010, 33 (Suppl. 1), S62-S69. [CrossRef] [PubMed]

4. Camli, B.; Kusakci, E.; Lafci, B.; Salman, S.; Torun, H.; Yalcinkaya, A.D. Cost-Effective, Microstrip Antenna Driven Ring Resonator Microwave Biosensor for Biospecific Detection of Glucose. IEEE J. Sel. Top. Quantum Electron. 2017, 23, 404-409. [CrossRef]

5. Teymourian, H.; Barfidokht, A.; Wang, J. Electrochemical glucose sensors in diabetes management: An updated review (20102020). Chem. Soc. Rev. 2020, 49, 7671-7709. [CrossRef] [PubMed]

6. McNichols, R.J.; Coté, G.L. Optical glucose sensing in biological fluids: An overview. J. Biomed. Opt. 2000, 5, 5-16. [CrossRef]

7. Ong, J.J.; Pollard, T.D.; Goyanes, A.; Gaisford, S.; Elbadawi, M.; Basit, A.W. Optical biosensors-Illuminating the path to personalized drug dosing. Biosens. Bioelectron. 2021, 188, 113331. [CrossRef] [PubMed]

8. Wang, J. Electrochemical Glucose Biosensors. Chem. Rev. 2008, 108, 814-825. [CrossRef] [PubMed]

9. Hwang, D.W.; Lee, S.; Seo, M.; Chung, T.D. Recent advances in electrochemical non-enzymatic glucose sensors-A review. Anal. Chim. Acta 2018, 1033, 1-34. [CrossRef] [PubMed]

10. Sharma, P.K.; Kim, E.-S.; Mishra, S.; Ganbold, E.; Seong, R.-S.; Kaushik, A.K.; Kim, N.-Y. Ultrasensitive and Reusable Graphene Oxide-Modified Double-Interdigitated Capacitive (DIDC) Sensing Chip for Detecting SARS-CoV-2. ACS Sens. 2021, 6, 3468-3476. [CrossRef]

11. Mehrotra, P.; Chatterjee, B.; Sen, S. EM-Wave Biosensors: A Review of RF, Microwave, mm-Wave and Optical Sensing. Sensors 2019, 19, 1013. [CrossRef]

12. Turgul, V.; Kale, I. Influence of fingerprints and finger positioning on accuracy of RF blood glucose measurement from fingertips. Electron. Lett. 2016, 53, 218-220. [CrossRef] 
13. Afroz, S.; Thomas, S.W.; Mumcu, G.; Saddow, S.E. Implantable SiC based RF antenna biosensor for continuous glucose monitoring. In Proceedings of the SENSORS, 2013 IEEE, Baltimore, MD, USA, 3-6 November 2013; pp. 1-4.

14. Hanna, J.; Bteich, M.; Tawk, Y.; Ramadan, A.H.; Dia, B.; Asadallah, F.A.; Eid, A.; Kanj, R.; Costantine, J.; Eid, A.A. Noninvasive, wearable, and tunable electromagnetic multisensing system for continuous glucose monitoring, mimicking vasculature anatomy. Sci. Adv. 2021, 6, eaba5320. [CrossRef]

15. Deshours, F.; Alquié, G.; Kokabi, H.; Rachedi, K.; Tlili, M.; Hardinata, S.; Koskas, F. Improved microwave biosensor for non-invasive dielectric characterization of biological tissues. Microelectron. J. 2019, 88, 137-144. [CrossRef]

16. Kumar, A.; Wang, C.; Meng, F.Y.; Zhou, Z.L.; Zhao, M.; Yan, G.F.; Kim, E.S.; Kim, N.Y. High-sensitivity, quantified, linear and mediator-free resonator-based microwave biosensor for glucose detection. Sensors 2020, 20, 4024. [CrossRef] [PubMed]

17. Sharafadinzadeh, N.; Abdolrazzaghi, M.; Daneshmand, M. Highly sensitive microwave split ring resonator sensor using gap extension for glucose sensing. In Proceedings of the 2017 IEEE MTT-S International Microwave Workshop Series on Advanced Materials and Processes for RF and THz Applications (IMWS-AMP), Pavia, Italy, 20-22 September 2017; pp. 1-3.

18. Liu, C.F.; Wang, M.H.; Jang, L.S. Microfluidics-based hairpin resonator biosensor for biological cell detection. Sens. Actuators $B$ Chem. 2018, 263, 129-136. [CrossRef]

19. Govind, G.; Akhtar, M.J. Metamaterial-Inspired Microwave Microfluidic Sensor for Glucose Monitoring in Aqueous Solutions. IEEE Sens. J. 2019, 19, 11900-11907. [CrossRef]

20. Dautta, M.; Alshetaiwi, M.; Escobar, J.; Tseng, P. Passive and wireless, implantable glucose sensing with phenylboronic acid hydrogel-interlayer RF resonators. Biosens. Bioelectron. 2020, 151, 112004. [CrossRef]

21. Kim, N.; Dhakal, R.; Adhikari, K.; Kim, E.S.; Wang, C. A reusable robust radio frequency biosensor using microwave resonator by integrated passive device technology for quantitative detection of glucose level. Biosens. Bioelectron. 2014, 67, 687-693. [CrossRef] [PubMed]

22. Salim, A.; Lim, S. Recent advances in the metamaterial-inspired biosensors. Biosens. Bioelectron. 2018, 117, 398-402. [CrossRef] [PubMed]

23. Lee, K.H.; Kim, E.S.; Liang, J.G.; Kim, N.Y. Design and realization of a compact high-frequency band-pass filter with low insertion loss based on a combination of a circular-shaped spiral inductor, spiral capacitor and interdigital capacitor. Electronics 2018, 7, 195. [CrossRef]

24. Mohan, S.S.; Hershenson, M.d.M.; Boyd, S.P.; Lee, T.H. Simple accurate expressions for planar spiral inductances. IEEE J. Solid-State Circuits 1999, 34, 1419-1424. [CrossRef]

25. Tang, W.; Zhu, Y.; Chow, Y.L. Inductance calculation of spiral inductors in different shapes. In Proceedings of the 2005 Asia-Pacific Microwave Conference Proceedings, Suzhou, China, 4-7 December 2005; Volume 5, p. 3.

26. Ong, K.G.; Grimes, C.A. A resonant printed-circuit sensor for remote query monitoring of environmental parameters. Smart Mater. Struct. 2000, 9, 421-428. [CrossRef]

27. McGregor, D.S.; Kammeraad, J.E. CHAPTER 10-Gallium Arsenide Radiation Detectors and Spectrometers. In Semiconductors and Semimetals; Elsevier: Livermore, CA, USA, 1995; Volume 43, pp. 383-442, ISBN 0080-8784.

28. Wang, H.C.; Lee, A.-R. Recent developments in blood glucose sensors. J. Food Drug Anal. 2015, 23, 191-200. [CrossRef]

29. Qiang, T.; Wang, C.; Kim, N.Y. Quantitative detection of glucose level based on radiofrequency patch biosensor combined with volume-fixed structures. Biosens. Bioelectron. 2017, 98, 357-363. [CrossRef]

30. Israelachvili, J.N. Intermolecular and Surface Forces; Academic Press: Cambridge, MA, USA, 1992.

31. Park, H.; Seo Yoon, H.; Patil, U.; Anoop, R.; Lee, J.; Lim, J.; Lee, W.; Chan Jun, S. Radio frequency based label-free detection of glucose. Biosens. Bioelectron. 2014, 54, 141-145. [CrossRef] [PubMed]

32. Ebrahimi, A.; Withayachumnankul, W.; Al-Sarawi, S.F.; Abbott, D. Microwave microfluidic sensor for determination of glucose concentration in water. In Proceedings of the 2015 IEEE 15th Mediterranean Microwave Symposium (MMS), Lecce, Italy, 30 November-2 December 2015; pp. 1-3.

33. Kumari, R.; Patel, P.; Yadav, R. An ENG Resonator-Based Microwave Sensor for the Characterization of Aqueous Glucose. J. Phys. D Appl. Phys. 2018, 51, 075601. [CrossRef]

34. Kim, J.; Babajanyan, A.; Hovsepyan, A.; Lee, K.; Friedman, B. Microwave dielectric resonator biosensor for aqueous glucose solution. Rev. Sci. Instrum. 2008, 79, 86107. [CrossRef] [PubMed]

35. Omer, A.E.; Shaker, G.; Safavi-Naeini, S.; Kokabi, H.; Alquié, G.; Deshours, F.; Shubair, R.M. Low-cost portable microwave sensor for non-invasive monitoring of blood glucose level: Novel design utilizing a four-cell CSRR hexagonal configuration. Sci. Rep. 2020, 10, 15200. [CrossRef]

36. Vrba, J.; Karch, J.; Vrba, D. Phantoms for Development of Microwave Sensors for Noninvasive Blood Glucose Monitoring. Int. J. Antennas Propag. 2015, 2015, 570870. [CrossRef]

37. Kim, S.; Melikyan, H.; Kim, J.; Babajanyan, A.; Lee, J.-H.; Enkhtur, L.; Friedman, B.; Lee, K. Noninvasive in vitro measurement of pig-blood d-glucose by using a microwave cavity sensor. Diabetes Res. Clin. Pract. 2012, 96, 379-384. [CrossRef] [PubMed]

38. Ebrahimi, A.; Scott, J.; Ghorbani, K. Microwave reflective biosensor for glucose level detection in aqueous solutions. Sens. Actuators A Phys. 2020, 301, 111662. [CrossRef]

39. Kaatze, U. Electromagnetic Wave Interactions with Water and Aqueous Solutions BT-Electromagnetic Aquametry: Electromagnetic Wave Interaction with Water and Moist Substances; Kupfer, K., Ed.; Springer: Berlin/Heidelberg, Germany, 2005; pp. 15-37, ISBN 978-3-540-26491-0. 
40. Hu, M.; Xiao, X.; Hang Song, Y.L. Microwave Non-Invasive Blood Glucose Detection Based on Debye Model. Laser Optoelectron. Prog. 2020, 57, 230401.

41. Turgul, V.; Kale, I. Characterization of the complex permittivity of glucose/water solutions for noninvasive RF/Microwave blood glucose sensing. In Proceedings of the 2016 IEEE International Instrumentation and Measurement Technology Conference Proceedings, Taipei, Taiwan, 23-26 May 2016; pp. 1-5.

42. Wang, C.; Ali, L.; Meng, F.Y.; Adhikari, K.K.; Zhou, Z.L.; Wei, Y.C.; Zou, D.Q.; Yu, H. High-accuracy complex permittivity characterization of solid materials using parallel interdigital capacitor-based planar microwave sensor. IEEE Sens. J. 2021, 21, 6083-6093. [CrossRef] 